\title{
Fungal community of necrotic and healthy galls in chestnut trees colonized by Dryocosmus kuriphilus (Hymenoptera, Cynipidae)
}

\author{
E Jordán Muñoz-Adalia ${ }^{(1)}$, \\ Daniel Rodríguez ${ }^{(2)}$, \\ María Casado (2), \\ Julio Diez ${ }^{(3-4)}$, \\ Mercedes Fernández ${ }^{(2-4)}$
}

\begin{abstract}
Dryocosmus kuriphilus is a non-native pest that has recently spread through Europe with a special incidence along the Mediterranean Basin. The presence of this exotic wasp (originally from Asia) threatens stands and orchards of sweet chestnut (Castanea sativa Mill.) as it reduces tree growth and consequently fruit production. In this study the living mycobiota in leaves, healthy and necrotic galls collected from two sites in Cantabria (Northern Spain) was investigated. A total of twenty-two fungal taxa based on morphological and molecular traits were determined. In addition, we calculated fungal diversity and identified the dominant taxa among members of the mycobiota. Seven loglinear models were used to analyse whether fungal abundance varied between sites, types of plant material or fungal taxa. Our findings highlight the complex interactions between plant hosts, insect and the endophytic community, and are of potential interest in relation to the biological control of this important pest.
\end{abstract}

Keywords: ACGW, Biological Control, Castanea sativa, Endophytic Fungi, Entomopathogens, Fungal Community, Necrotic Gall

\section{Introduction}

The Asian chestnut gall wasp (ACGW), Dryocosmus kuriphilus Yasumatsu (Hymenoptera: (ynipidae), a gall-inducing insect native of China, was first introduced to Japan, then North America and most recently to Europe (2002). Currently, ACGW has been spread to fourteen European countries including Spain. In this country the pest was first recorded in Catalonia, in

$\square$ (1) Forest Sciences Center of Catalonia (CTFC), Carretera St. Llorenç de Morunys, km.2, 25280 Solsona (Spain); (2) Department of Agroforestry Sciences, University of Valladolid. Avenida de Madrid 44, 34071 Palencia (Spain); (3) Department of Vegetal Production and Forest Resources, University of Valladolid. Avenida de Madrid 44, 34071 Palencia (Spain); (4) Sustainable Forest Management Research Institute, University of Valladolid INIA, Avenida de Madrid 44, 34071 Palencia (Spain)

\section{@ E Jordán Muñoz-Adalia (jordan.munoz@ctfc.es)}

Received: Dec 01, 2018 - Accepted: Jun 06, 2019

Citation: Muñoz-Adalia EJ, Rodríguez D, Casado M, Diez J, Fernández M (2019). Fungal community of necrotic and healthy galls in chestnut trees colonized by Dryocosmus kuriphilus (Hymenoptera, Cynipidae). iForest 12: 411-417. - doi: 10.3832/ifor3014-012 [online 2019-08-13]

Communicated by: Alberto Santini
2012 (Torrell \& Heras 2012), and then in Cantabria (Bezos et al. 2014). This invasive insect is now present in nine Autonomic Communities and fourteen provinces in the country. The female emerges over a relatively short period in early summer and immediately lays eggs inside the chestnut buds (Castanea sativa Mill.) that will develop during the following spring (Dixon et al. 1986, Maltoni et al. 2012, Panzavolta et al. 2012). The ACGW forms galls on leaves and shoots, thus halting growth and causing abortion of flowers and thereby reducing chestnut yield. The ACGW is the most important pest affecting Castanea species worldwide, with loss of chestnuts reaching $80 \%$ in cases of severe infestations (Dixon et al. 1986, Panzavolta et al. 2012).

Several attempts have been made to control this forest pest worldwide. In this regard, the parasitoid Torymus sinensis Kamijo (Hymenoptera, Torymidae), a natural enemy of the ACGW, has been shown to be an effective control agent in the medium or long term (Quacchia et al. 2008). However, the use of non-native species may have negative impacts on the native parasitoid community such as the risk of hybridization, hyperparasitism or displacement of native species. The search for novel biocontrol agents to manage the infestations of ACGW is therefore of great interest.

Alternative perspectives are offered by fungi, since endophytes sensu lato (i.e., fungi that inhabit plant tissues regardless their lifestyle and the kind of association established with the host) have been successfully used as biological control agents (BCAs - Arnold et al. 2003). Endophytes can be isolated from the same ecosystem in which they will be used as biological controllers, and thus no impact on the environment is expected. Comparing to the chemical control, another advantage is that organisms do not generally become resistant to the endophytes (Martínez-Alvarez et al. 2015). Moreover, endophytes can provide other benefits to the plants. For instance, many studies have demonstrated that the presence of specific groups of endophytes can promote high growth rates in plants (Barka et al. 2002), resistance to drought stress, defence against herbivores (Carroll 1988) as well as resistance against biotic and abiotic stresses (Swarthout et al. 2009).

Prospero \& Forster (2011) and Meyer et al. (2015) highlighted the relationship between the ACGW and the fungal community, by noting the link between the $D$. kuriphilus galls and increased infection by chestnut blight disease (Chryphonectria parasitica [Murrill] Barr). Unfortunately, the ecological impacts of invasive organisms are often analysed separately, thereby overlooking possible interactions and combined effects, which may considerably hinder the determination of actual ecological consequences (Meyer et al. 2015). Interactions between pathogenic organisms are specific to the tripartite insect-fungus-tree system (Hatcher 1995). The importance of fungi in the ecological balance of chestnut micoflora highlights the need of more scientific evidences about the species that colonize this host or their diversity.

The overall objectives of the present study were (i) to detect and identify endophytes colonizing $C$. sativa trees attacked 
by $D$. kuriphilus in two sites located in Northern Spain; (ii) to assess the diversity of the endophytic community; and (iii) to verify the predominant taxa among the fungi colonizing the galls for biological control purposes.

\section{Material and methods}

\section{Sample collection and fungal culture}

\section{Site 1}

Scattered chestnut trees surrounded by pine plantations of Monterey pine (Pinus radiata D. Don) were sampled between June and August 2015, in Vejorís (Cantabria, Northern Spain - Tab. 1). Necrotic galls (i.e., current season galls showing symptoms of degrading activity by fungi) were randomly collected every fortnight from up to ten trees depending on the abundance of necrotic galls. Healthy leaves were also randomly collected monthly in order to identify fungal taxa from asymptomatic tissue. Trees selected for gall collection showed neither symptoms of chestnut blight nor other relevant biotic damages. The galls and leaves were placed in labelled plastic bags and then held at $-20{ }^{\circ} \mathrm{C}$ until processing. The plant material was surface sterilized by immersion in $70 \% \mathrm{v} / \mathrm{v}$ ethanol for one minute, then in $2 \% \mathrm{v} / \mathrm{v}$ sodium hypochlorite for one minute, and finally in double distilled water for one minute. Each gall and leaf was then cut into four sections (galls) or nine $1-\mathrm{cm}^{2}$ pieces (leaves) and plated on PDA (3.90\% w/v potato-dextroseagar - Scharlab S.L., Spain) amended with streptomycin (PDAs, $0.60 \mathrm{~g} \mathrm{~L}^{-1}$ - Sigma Aldrich Química S.L., Spain) to reduce bacterial contamination of the plates. The cultures were incubated for five days at room temperature (i.e., $21 \pm 2{ }^{\circ} \mathrm{C}$ ). Incipient fungal colonies were then subcultured in new PDAs plates and incubated under the aforementioned conditions for one week.

\section{Site 2}

Necrotic galls were collected every fortnight between June and September 2016, in a chestnut plantation located in Zamudio

Tab. 1 - Description of sampled sites. (*): Climatic data of Santiurde de Toranzo, the closest location with climatic records; (**): summer values correspond to June-September period. Source of data: CLIMATE-DATA.ORG (https://es.climate-data.org/).

\begin{tabular}{lcc}
\hline Characteristics & $\begin{array}{c}\text { Site } 1 \\
(\text { Vejoris*) }\end{array}$ & $\begin{array}{c}\text { Site 2 } \\
\text { (Zamudio) }\end{array}$ \\
\hline ETRS89 & $43^{\circ} 11^{\prime} 46.65^{\prime \prime} \mathrm{N}$ & $43^{\circ} 17^{\prime} 55,76^{\prime \prime} \mathrm{N}$ \\
$03^{\circ} 53^{\prime} 29.01^{\prime \prime} \mathrm{W}$ & $02^{\circ} 51^{\prime} 04.66^{\prime \prime} \mathrm{W}$ \\
\hline Height (m a.s.l.) & 503 & 140 \\
\hline Annual rainfall $(\mathrm{mm})$ & 933 & 1194 \\
\hline Summer rainfall $(\mathrm{mm})^{* *}$ & 237 & 293 \\
\hline Mean temp. $\left({ }^{\circ} \mathrm{C}\right)$ & 13.8 & 14.0 \\
\hline Maximal temp. $\left({ }^{\circ} \mathrm{C}\right)$ & 23.2 & 23.4 \\
\hline Minimal temp. $\left({ }^{\circ} \mathrm{C}\right)$ & 5.5 & 6.3 \\
\hline Summer mean temp. $\left({ }^{\circ} \mathrm{C}\right)^{* *}$ & 18.6 & 18.9 \\
\hline Summer maximal temp. $\left({ }^{\circ} \mathrm{C}\right)^{* *}$ & 23.2 & 23.4 \\
\hline Summer minimal temp. $\left({ }^{\circ} \mathrm{C}\right)^{* *}$ & 13.9 & 14.5 \\
\hline
\end{tabular}

sisted on $7 \mathrm{~min}$ at $72{ }^{\circ} \mathrm{C}$. The protocol for LSU consisted on 3 min at $94{ }^{\circ} \mathrm{C}$; 36 cycles of $30 \mathrm{~s}$ at $94^{\circ} \mathrm{C}, 30 \mathrm{~s}$ at $54{ }^{\circ} \mathrm{C}, 1 \mathrm{~min}$ at $72^{\circ} \mathrm{C}$; and a last extension step of $10 \mathrm{~min}$ at $72{ }^{\circ} \mathrm{C}$. The resulting $P C R$ products were run in $1.60 \% \mathrm{w} / \mathrm{v}$ agarose gel stained with $0.004 \%$ (v/v) 10.000× GelRed ${ }^{\text {TM }}$ (Biotium, USA). DNA fragments were visualized under UV light, and the size of each amplicon was estimated by comparison against a $100 \mathrm{bp}$ ladder (Nippon Genetics Europe, Dueren, Germany).

Amplicons were sent to STAB Vida (http:// www.stabvida.com) for DNA purification and sequencing. Sequences were trimmed using Geneious Pro 6.0.6 (https://www.ge neious.com/) and compared against sequences deposited in GenBank (NCBI http://blast.ncbi.nlm.nih.gov/Blast.cgi) by using BLASTn and the Fungi database (taxid: 4751). Fungal taxa were assigned to genus or species level when they showed a homology equal or higher than $99 \%$ in at least one molecular marker. The sequences representing each OTU were submitted to GenBank (see Tab. S1 in Supplementary Material).

\section{Study of biological diversity}

The observed taxonomical richness (S) was calculated for each sampling site and type of material (leaves/healthy galls/necrotic galls). In addition, the fungal diversity and evenness were also calculated according to Shannon ( $\mathrm{H}$ and J respectively) and Simpson ( $D$ and $E$ respectively) indices (Zak \& Willing 2004).

Sample-based rarefaction curves were computed using EstimateS v9.10 software (http://viceroy.eeb.uconn.edu/estimates/), as described by Muñoz-Adalia et al. (2017). The similarity between mycobiota and plant material from different sites was evaluated using the Sorensen (I) and Jaccard $(Y)$ indices (Zak \& Willing 2004). Taxonomic dominance was also calculated using Camargo's index. According to this method, a single taxon is considered dominant if $p_{\mathrm{j}}>1 / \mathrm{S}$, where $p_{\mathrm{j}}$ is the number of isolates of taxon $j$ divided by the total number of fungal isolates. In addition, the functional group (i.e., guild) of each sampled taxon was investigated using the FUNGuild database (http://www.stbates.org/guilds/ app.php). When information of a single species was not available in the database, data referred to fungal genus was used for guild analysis.

\section{Statistical analysis}

The variation in fungal community composition was investigated by computing log-linear models in the $\mathrm{R}$ environment (https://www.r-project.org/). The absolute abundance of each taxon (i.e., number of colonies recorded for each taxon) was considered the response variable of each model. The sampling site, type of plant material (green or necrotic), fungal taxa and their corresponding interactions were selected as explanatory variables. Only mod- 
Tab. 2 - Abundance of each taxon of sampled mycobiota. Dominant taxa according to Camargo's index are indicated by an asterisk $\left({ }^{*}\right)$. FUNGuild categories: A (Animal pathogen); Ds (Dung saprotroph); En (Endophyte); Ep (Epiphyte); F (Fungal parasite); L (Lichen parasite); P (Plant pathogen); Ss (Soil saprotroph); U (Unidentified saprotroph); W (Wood saprotroph).

\begin{tabular}{|c|c|c|c|c|c|c|c|}
\hline \multirow[b]{2}{*}{ Fungal taxa } & \multicolumn{3}{|l|}{ Site 1} & \multicolumn{3}{|l|}{ Site 2} & \multirow{2}{*}{$\begin{array}{l}\text { Assigned guild } \\
\text { (FUNGuild) }\end{array}$} \\
\hline & $\begin{array}{l}\text { Green } \\
\text { leave }\end{array}$ & $\begin{array}{l}\text { Necrotic } \\
\text { gall }\end{array}$ & Total & $\begin{array}{l}\text { Green } \\
\text { gall }\end{array}$ & $\begin{array}{l}\text { Necrotic } \\
\text { gall }\end{array}$ & Total & \\
\hline Arthrinium arundinis* & ${ }^{*} 24(23.76 \%)$ & $1(0.46 \%)$ & $25(7.86 \%)$ & 0 & 0 & 0 & Ds/P \\
\hline Aureobasidium pullulans & 0 & 0 & 0 & $3(6.67 \%)$ & 0 & $3(4.23 \%)$ & A/En/Ep/P \\
\hline Bionectria byssicola & 0 & 0 & 0 & 0 & $1(3.85 \%)$ & $1(1.41 \%)$ & $F / U$ \\
\hline Cladosporium cladosporioides & 0 & 0 & 0 & $2(4.44 \%)$ & 0 & $2(2.82 \%)$ & $\mathrm{En} / \mathrm{Ep} / \mathrm{P}$ \\
\hline Colletotrichum acutatum ${ }^{*}$ & $2(1.98 \%)$ & *28 (12.90\%) & *30 (9.43\%) & *8 $(17.78 \%)$ & ${ }^{*} 4(15.38 \%)$ & *12 (16.90\%) & $\mathrm{En} / \mathrm{P}$ \\
\hline Daldinia concentrica & 0 & 0 & 0 & $1(2.22 \%)$ & 0 & $1(1.41 \%)$ & W \\
\hline Epicoccum nigrum & 0 & $5(2.30 \%)$ & $5(1.57 \%)$ & $1(2.22 \%)$ & $1(3.85 \%)$ & $2(2.82 \%)$ & $\mathrm{En} / \mathrm{L} / \mathrm{P}$ \\
\hline Fusarium sp.* & *20 (19.80\%) & $20(9.22 \%)$ & *40 (12.58\%) & 0 & 0 & 0 & $\mathrm{~A} / \mathrm{En} / \mathrm{L} / \mathrm{P} / \mathrm{Ss} / \mathrm{W}$ \\
\hline Fusarium lateritium & 0 & 0 & 0 & $1(2.22 \%)$ & 0 & $1(1.41 \%)$ & $\mathrm{En} / \mathrm{P}$ \\
\hline Gnomoniopsis castanea* & \multicolumn{4}{|c|}{ *27 (26.73\%) *103 (52.07\%)*130 (44.03\%)*17 (37.78\%) } & \multicolumn{2}{|c|}{ *7 $(26.92 \%) * 24(33.80 \%)$} & En \\
\hline Nigrospora oryzae & 0 & 0 & 0 & $2(4.44 \%)$ & 0 & $2(2.82 \%)$ & $\mathrm{En} / \mathrm{P}$ \\
\hline Paraphaeosphaeria neglecta & 0 & 0 & 0 & $1(2.22 \%)$ & $1(3.85 \%)$ & $2(2.82 \%)$ & U \\
\hline Penicillium glabrum & 0 & 0 & 0 & $1(2.22 \%)$ & $1(3.85 \%)$ & $2(2.82 \%)$ & $P$ \\
\hline Penicillium spinulosum & 0 & $1(0.46 \%)$ & $1(0.31 \%)$ & 0 & 0 & 0 & A \\
\hline Pestalotiopsis sp.* & $4(3.96 \%)$ & $3(1.38 \%)$ & $7(2.20 \%)$ & $3(6.67 \%)$ & $2(7.69 \%)$ & *5 (7.04\%) & $P$ \\
\hline Phoma herbarum & 0 & 0 & 0 & $1(2.22 \%)$ & 0 & $1(1.41 \%)$ & $P$ \\
\hline Rhizomucor variabilis & 0 & 0 & 0 & 0 & $1(3.85 \%)$ & $1(1.41 \%)$ & 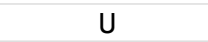 \\
\hline Sirococcus castaneae* & 0 & 0 & 0 & $3(6.67 \%)$ & *5 (19.23\%) & *8 (11.27\%) & $\mathrm{P}$ \\
\hline Sydowia polyspora* & 0 & 0 & 0 & $1(2.22 \%)$ & *3 (11.54\%) & $4(5.63 \%)$ & $P$ \\
\hline Trichoderma atroviride morphotype 1 & $2(1.98 \%)$ & 0 & $2(0.63 \%)$ & 0 & 0 & 0 & En \\
\hline Trichoderma atroviride morphotype $2^{*}$ & $9(8.91 \%)$ & *45 (20.74\%) & *54 (16.98\%) & 0 & 0 & 0 & En \\
\hline Mucor sp. like & 0 & $1(0.46 \%)$ & $1(0.31 \%)$ & 0 & 0 & 0 & $U$ \\
\hline Unknown001* & *13 $(12.87 \%)$ & 0 & $13(4.09 \%)$ & 0 & 0 & 0 & - \\
\hline Total positive samples & 101 & 217 & 318 & 45 & 26 & 71 & - \\
\hline
\end{tabular}

els that revealed significant effects of variables were investigated further. The most parsimonious model according to Akaike's Information Criteria (AIC) was selected as best model by the "AICcmodavg" package for R (Mazerolle 2017). This model was then compared with the other computed models by using the $\chi^{2}$ test in the same programming environment.

\section{Results}

Identification of fungal taxa A total of 35 necrotic galls from Site 1 were fragmented and cultured as previously outlined. As a result, 23 galls provided 148 fungal colonies and the others only produced bacterial masses being recorded as negative samples. In parallel, 12 healthy leaves from Site 1 were cultured after being cut in 108 fragments, which provided 101 fungal colonies. Twenty-four green galls from Site 2 were cultured in 96 pieces, of which 45 fragments produced fungal colonies. In the case of necrotic galls from Site 2, 24 fragmented galls yielded 26 isolates. In summary, 320 fungal colonies were identified and morphologi- cally grouped into 22 OTUs. Molecular identification of the OTUs by ITS and LSU markers resulted in 19 genera (Tab. 2 and Tab. S1 in Supplementary material).

\section{Biological diversity}

The sampled-based rarefaction curves approached an asymptote for both healthy leaves and necrotic galls in Site 1. By contrast, the curve for Site 2 was not asymptotic (Fig. 1, Fig. 2, Fig. 3, Fig. 4). Asymptotic curves indicate that sampling effort is sufficient for adequate characterization of the studied community. The analysis of varia-

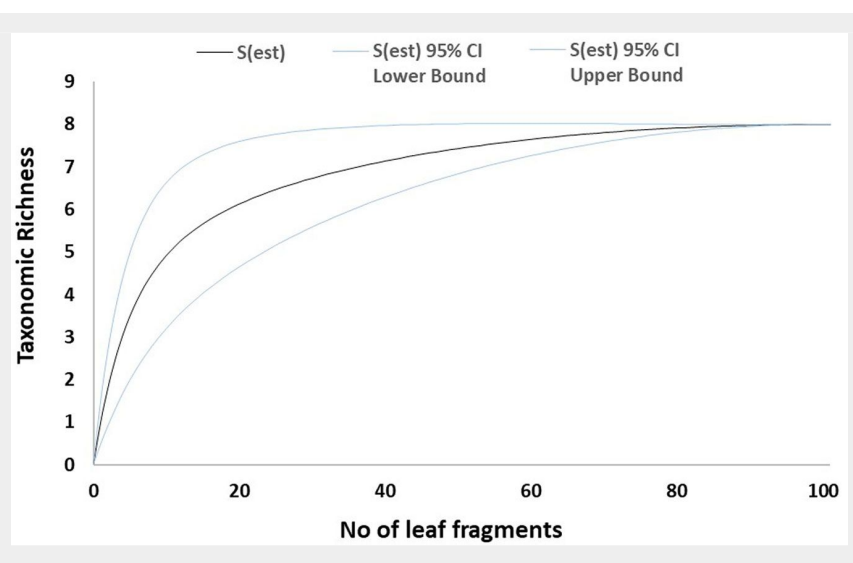

Fig. 1 - Mao-Tau estimator for healthy leaves from Site 1. Taxonomic accumulation curves for fungal taxa isolated from green leaves from Site 1 (Vejorís). Taxonomic richness computed using Mao-Tau estimator with $95 \%$ confidence intervals.

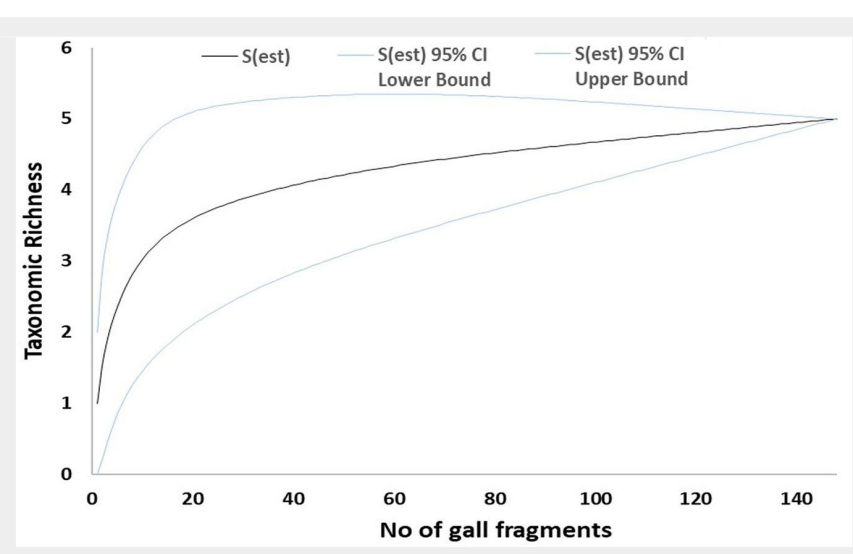

Fig. 2 - Mao-Tau estimator for necrotic galls from Site 1. Taxonomic accumulation curves for fungal taxa isolated from necrotic galls from Site 1 (Vejorís). Taxonomic richness computed using Mao-Tau estimator with $95 \%$ confidence intervals. 


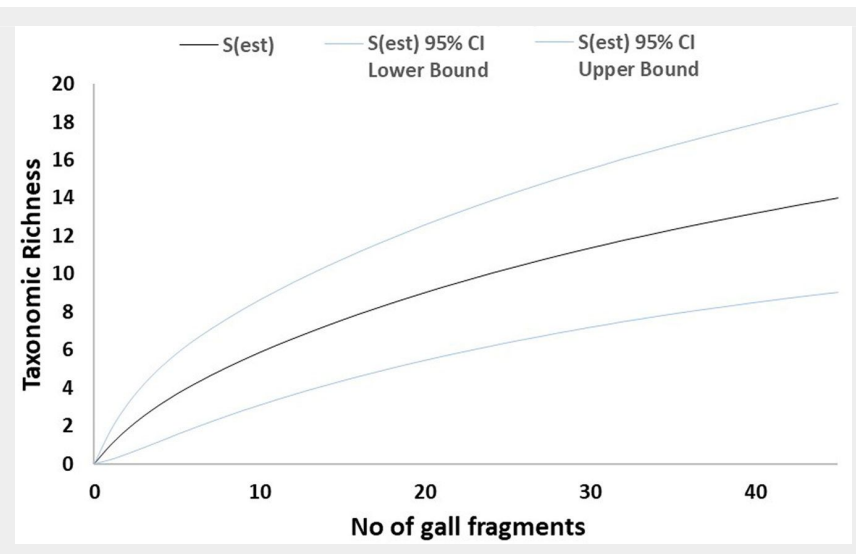

Fig. 3 - Mao-Tau estimator for green galls from Site 2. Taxonomic accumulation curves for fungal taxa isolated from green galls from Site 2 (Zamudio). Taxonomic richness computed using Mao-Tau estimator with 95\% confidence intervals.

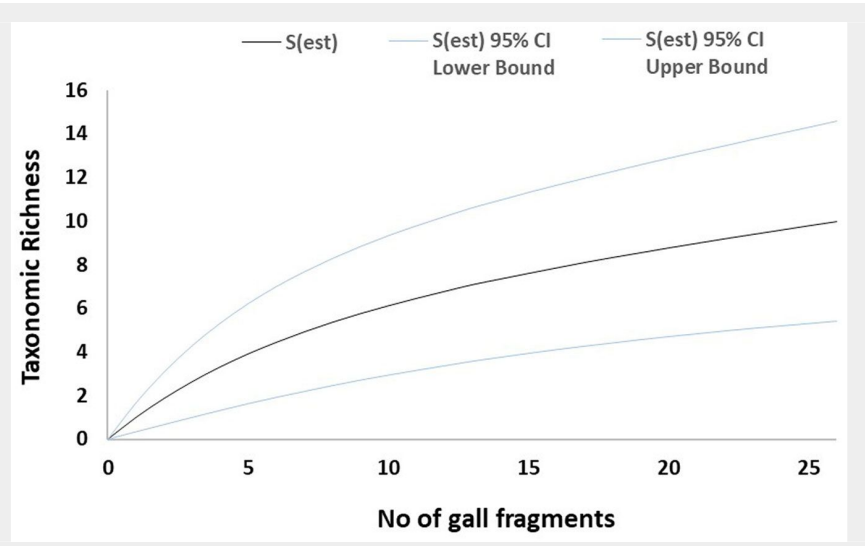

Fig. 4 - Mao-Tau estimator for necrotic galls from Site 2. Taxonomic accumulation curves for fungal taxa isolated from necrotic galls from Site 2 (Zamudio). Taxonomic richness computed using Mao-Tau estimator with $95 \%$ confidence intervals. tion of absolute abundance provided a to- test pairwise comparisons $(p<0.01)$.

tal of seven log-linear models. The most The most frequently isolated fungus was parsimonious model (i.e., Model 1 - Tab. 3) Gnomoniopsis castanea Tamietti (synonym: included the three factors considered (fun- Gnomoniopsis smithogilvyi L.A. Shuttlew., gal taxa, sampling site and type of plant E.C.Y. Liew \& D.I. Guest), which dominated material) but no interactions between the whole community according to Cathem as explanatory variables. In addition, margo's index (Sites 1 and 2). The domithis model was also significantly different nant taxa in Site 1 were G. castanea, Trichofrom the other models computed in all $\chi^{2}$ derma atroviride P. Karst morphotype 2,

Tab. 3 - Log-linear model selection of absolute fungal abundance as response variable. $(\times)$ : interaction of variables; (K): number of parameters; (AICC): corrected Akaike information criterion; $(\triangle \mathrm{AIC})$ : difference of AIC between each model and the model with the lowest AIC; $\left(\mathrm{w}_{\mathrm{i}}\right)$ : Akaike weights.

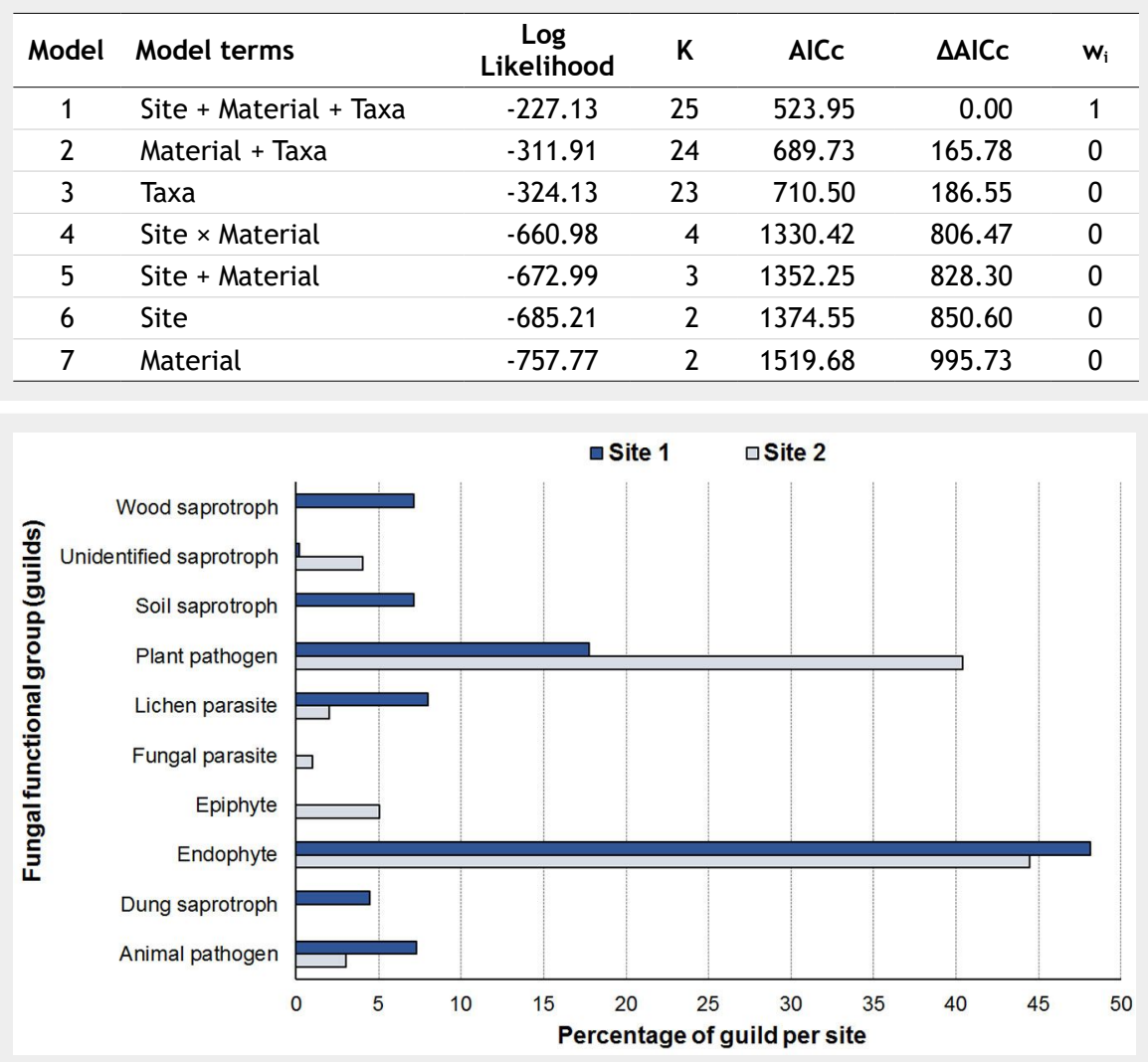

Fig. 5 - Relative abundance of each functional group (guild). Source of data: FUNGuild database (http://www.stbates.org/guilds/app.php).
Fusarium sp. and Colletotrichum acutatum J.H. Simmonds, whereas G. castanea, C. acutatum, Sirococcus castaneae (Prill. \& Delacr.) J.B. Mey., Senn- Irlet \& T.N. Sieber and Pestalotiopsis sp. were the dominant species in Site 2 (Tab. 2). On the other hand, the similarity between studied sites was rather low $(\mathrm{I}=0.30, \mathrm{Y}=0.17)$.

Analysis of the guilds revealed 10 functional groups in sampled mycobiota (Tab. 2). The endophytes and plant pathogens were the most representative groups, with abundances of $48.13 \%$ and $17.75 \%$ respectively in Site 1 and $44.43 \%$ and $40.40 \%$ respectively in Site 2 (Fig. 5).

\section{Discussion}

In this study we described the mycobiota associated with chestnuts infested by ACGW in two different sites in Northern Spain. The observed fungal diversity was moderate to high, relative to endophytic communities affecting other broadleaf species (Matsumura \& Fukuda 2013). More specifically, the Shannon diversity was lower than reported for Quercus species and Eurya japonica Hort. ex K. Koch in the aforementioned study. By contrast, taxonomic evenness was similar to those reported in that study due to the high dominance of a few taxa. Similarly, endophytic community found in twigs of Pinus sylvestris L. by Sanz-Ros et al. (2015) were also more diverse than in the present study. There were also slight differences in Shannon index values obtained in the present study and for mycobiota isolated from needles of Picea abies (L.) H. Karst. (Koukol et al. 2012). Therefore, we believe that the diversity of the mycobiota sampled can be considered moderate. Nevertheless, communities from different host species and tissues should be compared carefully.

Regarding the sampling effort and observed taxonomic richness, the results reported here suggest that the amount of plant material cultured may be enough to characterize the fungal community in Vejorís (Cantabria) for which sample-based 
rarefaction curves tended to plateau (Fig. 1, Fig. 2). By contrast, the curves for Zamudio (País Vasco) did not tend to be asymptotic, suggesting that more taxa may have been recorded if more plant material had been cultured (Fig. 3, Fig. 4). The statistical analysis showed high variability in fungal abundance for sampling site and plant material. The significant effect of site may be related to climate conditions as the summers are slightly drier in Vejorís (Site 1) and the sampling area is located at a higher altitude (by $\sim 360 \mathrm{~m}$ a.s.l.) than in Zamudio (Site 2 - Tab. 1). The sites also differed in habitat structure (i.e., scattered chestnut trees surrounded by Pinus spp. stands in Vejorís in contrast to monospecific chestnut plantation in Zamudio). These variations in host distribution may also explain the observed differences between communities as forest fragmentation is an important factor in the establishment of the mycobiota (Matsumura \& Fukuda 2013). In addition, the host genotype is another source of variation in endophytic communities that should not be overlooked (Bailey et al. 2005). The statistical analysis manifested that the type of plant material modulated the abundance of fungal taxa (Tab. 3). Our findings are consistent with those of Lawson et al. (2014), who reported that the composition of the endophytic community varied greatly depending on the tissue sampled (leaf vs. aphid gall vs. petiole) in poplars (Populus spp.). Regarding these data, we consider that the aforementioned environmental conditions (specially the type of plant material) probably act as selective factors modulating the composition of the mycobiota sampled (Terhonen et al. 2011). This phenomenon may explain the low similarity between sites shown by the Sorensen and Jaccard indices (both $\leq 0.30$ ). Here, we did not evaluate the effect of time in fungal communities since we sampled each mycobiota for a single season. Hence, future studies are required to elucidate changes in mycobiota composition in longer temporal series (e.g., from incipient infestation of ACGW until the stabilization of its populations).

The guild analysis confirmed that endophytes were the most abundant functional group of fungi inhabiting leaves and galls of C. sativa. Several taxa such as Aureobasidium pullulans (de Bary) G. Arnaud, Epicoccum nigrum Link, Fusarium spp., Phoma herbarum Westend., S. castaneae, Penicillium spp. and Trichoderma spp. have a welldocumented role as endophytes of different hosts, including chestnuts (Bissegger \& Sieber 1994, Botella \& Diez 2011, Lawson et al. 2014, Sanz-Ros et al. 2015). Surprisingly, plant pathogens were another major group regarding relative abundance, rather than plant saprotrophs as we expected. The abundance of opportunistic pathogens may be explained by an efficient use of gall-derived nutrients (mainly starch) as suggested for endophytes in other pathosystems (Hata \& Futai 1995). One of the dominant species was G. castanea, which has been reported to be a causal agent of canker in C. sativa (Pasche et al. 2016). The genus is thought to be closely associated with the spread of $D$. kuriphilus (Seddaiu et al. 2017). In addition, Magro et al. (2010) reported blight symptoms in twigs and intense necrosis in the $90 \%$ of galls inoculated with an undescribed member of this fungal genus. These results showed the probable participation of this genus as a latent pathogen that utilizes nutrients made available during gall formation. Gaffuri et al. (2015) observed the rapid colonization of galls by C. acutatum but did not observe natural necrosis due to this fungus in uninoculated galls. In contrast, this fungus was frequently found in naturally necrotized specimens. The presence of this species highlights the ecological plasticity of this fungus and its potential role as an opportunistic pathogen. The ecological complexity of the sampled mycobiota increases further on considering interactions between species (e.g., fungus-fungus; treefungus). In this regard, some community species such as Arthrinium arundinis (Corda) Dyko \& B. Sutton, P. herbarum, Sydowia polyspora (Bref. \& Tavel) E. Müll. and $S$. castaneae show multiple different types of behaviour, acting as saprotrophs, endophytes or pathogens depending on the host (Vikrant et al. 2006, Meyer et al. 2017). In addition, the presence of fungi with antagonistic activity can also modify the abundance of pathogenic taxa. Specifically, T. atroviride has a well-known antifungal effect (Kexiang et al. 2002) and its dominance in Site 1 could affect the abundance of other taxa. All these considerations deserve further study to elucidate the ecological role of each species during infestation by this invasive pest.

Entomopathogenic fungi comprise an interesting group among the sampled mycobiota. For example, C. acutatum was able to infect larvae of $D$. kuriphilus causing mortality (Graziosi \& Rieske 2015). In an earlier study, Marcelino et al. (2009) reported the entomopathogenic effect of a single variety of this fungus against Fiorinia externa Ferris (Hemiptera, Diaspididae), which acted as an endophyte or caused minor damage in plant hosts. These results support the possible use of this cosmopolitan epiphyte/endophyte as a biocontrol agent. Nevertheless, it also acts as a postharvest pathogen by colonizing healthy fruits (Gaffuri et al. 2017) thus hindering its use as biological control agent. Pestalotiopsis sp. has also proved to be a successful entomopathogen for Hemiberlesia pitysophila Takagi (Hemiptera, Diaspididae - Lv et al. 2011), producing average mortality rates of up to $67 \%$. The authors considered that the Pestalotiopsis sp. strains used did not damage the host, even though this genus is considered a conifer pathogen. Our findings suggest that the Fusarium spp. were not acting as entomopathogens as they were abundantly represented in
Site 1, but not in Site 2 where they were not present in necrotic galls. These findings differ from those reported by Addario \& Turchetti (2011), who showed promising results using the Fusarium incarnatum-equiseti species complex in necrotic galls. Tosi et al. (2015) also isolated Fusarium proliferatum (Matsush.) Nirenberg from galls and the fungus was often seen covering the insects' bodies. Cladosporium cladoporioides also showed entomopathogenic potential for controlling the mite Tetranychus urticae Koch (Acari, Tetranychidae), in which it caused mortality $>50 \%$, indicating the species as a candidate biocontrol agent worthy of future study (Eken \& Hayat 2009). In this regard, it is important to note that any candidate species could also affect native or exotic parasitoids of ACGW, playing a plausible counterproductive role that should not be neglected. Despite the previously mentioned pathogenic role of Gnomoniopsis sp. (Visentin et al. 2012), G. castanea proved to be a successful entomopathogenic fungi against $D$. kuriphilus in a recent study performed in Italy (Vannini et al. 2017), in which mortality reached $>60 \%$, and was particularly high in the adult wasps. Nevertheless, the authors mentioned that the failure of adults to emerge may be related to the dry state of gall tissues. This would support the possible interaction of other fungi that consume nutrients in the gall as secondary actors in the aetiology and possible control of the chestnut gall wasp.

\section{Conclusions}

The mycobiota associated with C. sativa infested by $D$. kuriphilus in two different sites in Northern Spain was moderately diverse and dominated by a few taxa, including the chestnut pathogen G. castanea.

The taxonomic composition of studied communities varied among locations and type of plant tissue. Together these results suggest an intense effect of environmental and temporal factors that should be considered for a complete characterization of fungal community associated with ACGW.

Fungal endophytes and plant pathogens were the best represented guilds among the identified taxa. Several taxa with entomopathogenic potential were detected in the sampled mycobiota deserving further study.

\section{Acknowledgements}

The authors thank Milagros de Vallejo and Juan Blanco (Gobierno de Cantabria, Spain) for their help in carrying out the study. The authors also thank J. Asdrúbal Flores-Pacheco (Bluefields Indian and Caribbean University, Nicaragua), Juan Carlos Vinagrero and Beatriz Fernández-Duque (University of Valladolid, Spain), for their participation in the fieldwork. The authors are also grateful to three anonymous reviewers for their helpful comments on an earlier version of the article. 


\section{Author contributions}

EJM-A, JD and MF conceived and designed the experiment; EJM-A and DR performed the experiment; EJM-A, DR and MC analysed the data; EJM-A, MC, JD and MF wrote the paper and edited the manuscript.

\section{References}

Addario E, Turchetti T (2011). Parasitic fungi on Dryocosmus kuriphilus in Castanea sativa necrotic galls. Bulletin of Insectology 64: 269273. [online] URL: http://www.bulletinofinsec tology.org/pdfarticles/vol64-2011-269-273addar io.pdf

Arnold AE, Mejía LC, Kyllo D, Rojas El, Maynard Z, Robbins N, Herre EA (2003). Fungal endophytes limit pathogen damage in a tropical tree. Proceedings of the National Academy of Sciences USA 100 (26): 15649-15654. - doi: 10.1073/pnas.2533483100

Bailey JK, Deckert R, Schweitzer JA, Rehill BJ, Lindroth RL, Gehring C, Whitham TG (2005). Host plant genetics affect hidden ecological players: links among Populus, condensed tannins, and fungal endophyte infection. Canadian Journal of Botany 83 (4): 356-361. - doi: 10.1139/ b05-008

Barka EA, Gognies S, Nowak J, Audran JC, Belarbi $A$ (2002). Inhibitory effect of endophytic bacteria on Botrytis cinerea and its influence to promote the grapevine growth. Biological Control 24 (2): 135-142. - doi: 10.1016/S1049-9644 (02)00034-8

Bezos D, Diez JJ, Fernández MM (2014). Possibilities of biological control on Dryocosmus kuriphilus with entomopathogenic fungi. In: Proceedings of the " 2 nd International Meeting on Dryocosmus kuriphilus Yasumatsu". Biocastanea, Ponferrada (León, Spain) 12-16 Nov 2014, Meeting Program, pp. 2.

Bissegger M, Sieber TN (1994). Assemblages of endophytic fungi in coppice shoots of Castanea sativa. Mycologia 86 (5): 648-655. - doi: 10.108 o/00275514.1994.12026464

Botella L, Diez JJ (2011). Phylogenic diversity of fungal endophytes in Spanish stands of Pinus halepensis. Fungal Diversity 47: 9-18. - doi: 10.10 07/s13225-010-0061-1

Carroll G (1988). Fungal endophytes in stems and leaves: from latent pathogen to mutualistic symbiont. Ecology 69: 2-9. - doi: 10.2307/194 3154

Dixon WN, Burns RE, Stange LA (1986). Oriental chestnut gall wasp, Dryocosmus kuriphilus Yasumatsu (Hymenoptera: Cynipidae). Entomology Circular, Division of Plant Industry, Florida Department of Agriculture and Consumer Services 287: 1-2. [online] URL: http://www.cab direct.org/cabdirect/abstract/19880546342

Eken C, Hayat R (2009). Preliminary evaluation of Cladosporium cladosporioides (Fresen.) de Vries in laboratory conditions, as a potential candidate for biocontrol of Tetranychus urticae Koch. World Journal of Microbiology and Biotechnology 25 (3): 489-492. - doi: 10.1007/s112 74-008-9914-0

Gaffuri F, Maresi G, Pedrazzoli F, Longa C, Boriani M, Molinari M, Tantardini A (2015). Colletotrichum acutatum associated with Dryocosmus kuriphilus galls on Castanea sativa. Forest
Pathology 45 (2): 169-171. - doi: 10.1111/efp.12178 Gaffuri F, Longa CMO, Turchetti T, Danti R, Maresi G (2017). "Pink rot": infection of Castanea sativa fruits by Colletotrichum acutatum. Forest Pathology 47: e12307. - doi: 10.1111/efp.12307

Graziosi I, Rieske LK (2015). A plant pathogen causes extensive mortality in an invasive insect herbivore. Agricultural and Forest Entomology 17 (4): 366-374. - doi: 10.1111/afe.12116

Hata K, Futai K (1995). Endophytic fungi associated with healthy pine needles and needles infested by the pine needle gall midge, Thecodiplosis japonensis. Canadian Journal of Botany 73: 384-39o. - doi: 10.1139/b95-040

Hatcher PE (1995). Three-way interactions between plant-pathogenic fungi, herbivorous insects and their host plants. Biological Reviews 70 (4): 639-694. - doi: 10.1111/j.1469-185X.1995. tbo1655.x

Kexiang G, Xiaoguang L, Yonghong L, Tianbo Z, Shuliang W (2002). Potential of Trichoderma harzianum and T. viride to control Botryosphaeria berengeriana f. sp. piricola, the cause of apple ring rot. Journal of Phytopathology 150: 271-276. - doi: 10.1046/j.1439-0434.2002.0 0754.x

Koukol $\mathrm{O}$, Kolarík $\mathrm{M}$, Kolárová $\mathrm{Z}$, Baldrian $\mathrm{P}$ (2012). Diversity of foliar endophytes in windfallen Picea abies trees. Fungal Diversity 54: 6977. - doi: 10.1007/s13225-011-0112-2

Lacap DC, Hyde KD, Liew ECY (2003). An evaluation of the fungal "morphotype" concept based on ribosomal DNA sequences. Fungal Diversity 12: 53-66. [online] URL: http://www. fungaldiversity.org/fdp/sfdp/FD12-53-66.pdf Lawson SP, Christian N, Abbot P (2014). Comparative analysis of the biodiversity of fungal endophytes in insect-induced galls and surrounding foliar tissue. Fungal Diversity 66: 89-97. doi: 10.1007/s13225-013-0268-z

Lv C, Huang B, Qiao M, Wei J, Ding B (2011). Entomopathogenic Fungi on Hemiberlesia pitysophila. PLoS ONE 6 (8): e23649. - doi: 10.1371/ journal.pone.0023649

Magro P, Speranza S, Stacchiotti M, Martignoni D, Paparatti B (2010). Gnomoniopsis associated with necrosis of leaves and chestnut galls induced by Dryocosmus kuriphilus. Plant Pathology 59: 1171-1171. - doi: 10.1111/j.1365-3059.2010. 02336.x

Maltoni A, Mariotti B, Tani A (2012). Case study of a new method for the classification and analysis of Dryocosmus kuriphilus Yasumatsu damage to young chestnut sprouts. iForest 5: 5059. - doi: 10.3832/iforo598-008

Marcelino JAP, Gouli S, Parker BL, Skinner M, Schwarzberg L, Giordano R (2009). Host plant associations of an entomopathogenic variety of the fungus, Colletotrichum acutatum, recovered from the elongate hemlock scale, Fiorinia externa. Journal of Insect Science 9 (25): 1-11. doi: 10.1673/031.009.2501

Martínez-Álvarez P, Fernández-González RA, Sanz-Ros AV, Pando V, Diez JJ (2015). Two fungal endophytes reduce the severity of pitch canker disease in Pinus radiata seedlings. Biological Control 94: 1-10. - doi: 10.1016/j.biocontr ol.2015.11.011

Matsumura E, Fukuda K (2013). A comparison of fungal endophytic community diversity in tree leaves of rural and urban temperate forests of
Kanto district, eastern Japan. Fungal Biology 117 (3): 191-20. - doi: 10.1016/j.funbio.2013.01.007 Mazerolle MJ (2017). AlCcmodavg: Model selection and multimodel inference based on (Q)AIC(c). R package version 2.1-1. [online] URL: http://cran.r-project.org/package=AICcmodavg/ Meyer JB, Gallien L, Prospero S (2015). Interaction between two invasive organisms on the European chestnut: does the chestnut blight fungus benefit from the presence of the gall wasp? FEMS Microbiology Ecology 91 (11): fiv 122. - doi: 10.1093/femsec/fiv122

Meyer JB, Trapiello E, Senn-Irlet B, Sieber TN, Cornejo C, Aghayeva D, González AJ, Prospero $S$ (2017). Phylogenetic and phenotypic characterisation of Sirococcus castaneae comb. nov. (synonym Diplodina castaneae), a fungal endophyte of European chestnut. Fungal Biology 121 (8): 625-637. - doi: 10.1016/j.funbio.2017.04.001 Muñoz-Adalia EJ, Sanz-Ros AV, Flores-Pacheco JA, Hantula J, Diez JJ, Vainio EJ, Fernández M (2017). Sydowia polyspora dominates fungal communities carried by two Tomicus species in pine plantations threatened by Fusarium circinatum. Forests 8 (4): 127-142. - doi: 10.339o/f8 040127

Panzavolta T, Bracalini M, Croci F, Campani C, Bartoletti T, Miniati G, Benedettelli S, Tiberi R (2012). Asian chestnut gall wasp in Tuscany: gall characteristics, egg distribution and chestnut cultivar susceptibility. Agricultural and Forest Entomology 14: 139-145. - doi: 10.1111/j.14619563.2011.00551.x

Pasche S, Calmin G, Auderset G, Crovadore J, Pelleteret P, Mauch-Mani B, Barja F, Paul B, Jermini $M$, Lefort $F$ (2016). Gnomoniopsis smithogilvyi causes chestnut canker symptoms in Castanea sativa shoots in Switzerland. Fungal $\mathrm{Ge}$ netics and Biology 87: 9-21. - doi: 10.1016/j. fgb.2016.01.002

Prospero S, Forster B (2011). Chestnut gall wasp (Dryocosmus kuriphilus) infestations: new opportunities for the chestnut blight fungus Cryphonectria parasitica? New Disease Reports 23: 35. - doi: 10.5197/j.2044-0588.2011.023

Quacchia A, Moryia S, Bosio G, Scapin I, Alma A (2008). Rearing, release and the prospect of establishment of Torymus sinensis, biological control agent of the chestnut gall wasp Dryocosmus kuriphilus, in Italy. BioControl 53 (6): 829839. - doi: 10.1007/s10526-007-9139-4

Sanz-Ros AV, Müller MM, San Martín R, Diez JJ (2015). Fungal endophytic communities on twigs of fast and slow growing Scots pine (Pinus sylvestris $L$.) in northern Spain. Fungal Biology 119 (10): 870-883. - doi: 10.1016/j.funbio. 2015.06.008

Seddaiu S, Cerboneschi A, Sechi C, Mello A (2017). Gnomoniopsis castaneae associated with Dryocosmus kuriphilus galls in chestnut stands in Sardinia (Italy). iForest 10: 440-445. - doi: 10.3832/ifor2064-009

Swarthout D, Harper E, Judd S, Gonthier D, Shyne R, Stowe T, Bultman T (2009). Measures of leaf-level water-use efficiency in drought stressed endophyte infected and non-infected tall fescue grasses. Environmental and Experimental Botany 66: 88-93. - doi: 10.1016/j.env expbot.2008.12.002

Terhonen E, Marco T, Sun H, Jalkanen R, Kasanen R, Vuorinen M, Asiegbu F (2011). The effect 
of latitude, season and needle-age on the mycota of Scots pine (Pinus sylvestris) in Finland. Silva Fennica 45 (3): 301-317. - doi: 10.14214/ sf.104

Torrell A, Heras J (2012). Vespeta del castanyer; Dryocosmus kuriphilus. [The chestnut wasp, Dryocosmus kuriphilus]. Generalitat de Catalunya, Department of Agriculture, Livestock, Fisheries, Food and Natural Environment, Forest Management Service and the Plant Health Service, Barcelona, Catalunya, Spain, pp. 1-2. [in Spanish]

Tosi L, Beccari G, Rondoni G, Covarelli L, Ricci C (2015). Natural occurrence of Fusarium proliferatum on chestnut in Italy and its potential entomopathogenicity against the Asian chestnut gall wasp Dryocosmus kuriphilus. Journal of Pest Science 88 (2): 369-381. - doi: 10.1007/ s10340-014-0624-0
Vainio EJ, Korhonen K, Hantula J (1998). Genetic variation in Phlebiopsis gigantea as detected with random amplified microsatellite (RAMS) markers. Mycological Research 102 (2): 187-192. - doi: 10.1017/S0953756297004577

Vannini A, Vettraino AM, Maritgnoni D, MoralesRodriguez C, Contarini M, Cacci R, Paparatti B, Speranza S (2017). Does Gnomoniopsis castanea contribute to the natural biological control of chestnut gall wasp? Fungal Biology 121: 44-52. doi: 10.1016/j.funbio.2016.08.013

Vikrant P, Verma KK, Rajak RC, Pandey AK (2006). Characterization of a phytotoxin from Phoma herbarum for management of Parthenium hysterophorus L. Journal of Phytopathology 154: 1-8. - doi: 10.1111/j.1439-0434.2006.01 129.x

Visentin I, Gentile S, Valentino D, Gonthier P, Tamietti G, Cardinale FF (2012). Gnomoniopsis cas- tanea sp. nov. (Gnomoniaceae, Diaporthales) as the causal agent of nut rot in sweet chestnut. Journal of Plant Pathology 94 (2): 411-419. [online] URL: http://www.sipav.org/main/jpp/inde x.php/jpp/article/view/2569

Zak JC, Willing MR (2004). Fungal Biodiversity Patterns. In: "Biodiversity of Fungi: Inventory and Monitoring Methods" (Mueller GM, Bills GF, Foster MS eds). Elsevier Academic Press, Burlington, MA, USA, pp. 59-75. - doi: 10.1016/ B978-012509551-8/50008-8

\section{Supplementary Material}

Tab. S1 - List of the fungal taxa identified in the study.

Link: Munoz-Adalia_3014@supplo01.pdf 